\title{
Evaluation of osteoporosis using DEXA scan among low income group women in South India
}

\author{
Pavalan Louis ${ }^{1}$, Vetrivel Chezian Sengodan ${ }^{2 *}$, Nanda Kumar T ${ }^{3}$, Sharan Achar T ${ }^{4}$ \\ ${ }^{1}$ Professor, ${ }^{2}$ Director and Professor, ${ }^{3}$ Junior Resident, Dept. of Orthopaedics, ${ }^{1}$ Thoothukudi Medical College and Hospital, Thoothukudi, \\ Tamil Nadu, ${ }^{2-4}$ Institute of Orthopaedics and Traumatology, Coimbatore Medical College and Hospital, Coimbatore, Tamil Nadu, India \\ *Corresponding Author: S. Vetrivel Chezian \\ Email: svcortho@gmail.com
}

\begin{abstract}
Introduction and Objectives: Osteoporosis is one of the most common consequences of menopause and is characterized by low bone mass with micro architectural deterioration of bone tissue leading to bone fragility. Hip fracture is the worst complication of osteoporosis, with substantial morbidity and high one-year mortality. Hence it is essential to identify post-menopausal women at risk of developing osteoporosis. Dual energy x-ray absorptiometry (DEXA) is a valuable tool for screening women prone to osteoporosis. The objective of the present work was to estimate the prevalence of low bone mass in low income Indian women above 40 years for the assessment of osteoporosis and fracture risk using DEXA scan.

Materials and Methods: This study was conducted in Coimbatore from 2012-2017 with a sample size of 500 patients for the diagnosis of osteoporosis in low income group women from 40 to 70 years. Bone mineral density was done using DEXA Scan (Hologic) at lumbar spine and hip zones.

Results: The prevalence of osteoporosis in our study by hip BMD score was $38 \%$ and osteopenia was $24 \%$ and by spine BMD score osteoporosis was 36\% and osteopenia was 38\%. Overall, in the age group of between 41 and 65 years, the prevalence of osteopenia (36\%) and osteoporosis (30\%) together was $66 \%$, which is higher than other developed countries.

Conclusion: Risk of osteoporosis among women from the age of 40 years can be identified by DEXA scan method so that effective therapeutic measures can be initiated at the earliest.
\end{abstract}

Keywords: DEXA, Osteoporosis, South India.

\section{Introduction}

Osteoporosis is a 'silent disease' which clinically presents as fracture due to trivial trauma. ${ }^{1}$ The mean age of osteoporotic fractures among women from the low socioeconomic groups in India is around 59 years compared to 75 years in the west. In India, osteoporosis is highly prevalent with an estimated 30 million women diagnosed to have osteoporosis with high prevalence of osteopenia (52\%) and osteoporosis (29\%) thought to be due to inadequate nutrition. ${ }^{2,3}$ Hence, it is critically important to diagnose osteoporosis at the earliest. Bone mineral density accounts for $70 \%$ of bone strength, hence low bone mineral density is the greatest predictor of risk for bone fractures. ${ }^{4}$

Dual energy X-ray absorptiometry (DEXA) technology, the gold standard for diagnosing osteoporosis by measuring bone density. ${ }^{5}$ Its a useful tool for both the axial and appendicular skeleton as the detection rate of osteopenia and osteoporosis is higher with it in comparison to calcaneal quantitative ultrasound (QUS) method. ${ }^{6}$

\section{Risk factors associated with generalized osteoporosis Non Modifiable}

Personal history of fracture as an adult, History of fracture in first degree relative, female sex, advanced age, Caucasian race, Dementia

\section{Potentially Modifiable}

Current cigarette smoking, Low body weight $(<58 \mathrm{~kg})$, Estrogen deficiency, Early menopause $(<45 \mathrm{yrs})$ or bilateral ovariectomy, Prolonged premenstrual amenorrhea (>1year), Low calcium intake, Alcoholism, Impaired eye sight,
Recurrent falls, Inadequate physical activity, Poor health / frailty.

\section{DEXA Study}

The BMD is determined by DEXA using two x-ray beams of $70 \mathrm{keV}$ and $140 \mathrm{keV}$ respectively, which are fired on to the site of measurement after a time lag of $4 \mathrm{~ms}$. In Lunar DPX Densitometer two $\mathrm{x}$-ray energy levels are generated by kedge filtering technique. ${ }^{7}$ The $\mathrm{x}$-rays pass through the soft tissues and the bones, and the detector (Scintillation counter consisting of 32 element detector array made of Cadmium tungstate - CdWO4) detects the attenuation of the two beams and separates bone mineral content from soft tissue mass by measuring the difference in the attenuation of two energy levels.

In clinical practice, BMD measurements are widely used to diagnose osteoporosis and measurement in bone mass are commonly used as a surrogate for fracture risk. ${ }^{8}$ BMD is the measured parameter, and allows the calculation of the bone mineral content (BMC) in grams and the twodimensional projected area in $\mathrm{cm} 2$ of the bone(s) being measured; thus the units of BMD are $\mathrm{g} / \mathrm{cm} 2$. The BMD values (in $\mathrm{g} / \mathrm{cm} 2$ ) are not used for diagnosing osteoporosis. Instead, a working group of the WHO proposed to define osteoporosis on the basis of the T-score (which is the difference between the measured BMD and the mean value of young adults, expressed in standard deviations (SD) for a normal population of the same gender and ethnicity). Despite its limitations; this definition, which concerns only 
postmenopausal women and men over 50, is currently applied worldwide (Table 1).

DEXA has proven so far reasonably precise (about 1$2 \%$ ) and accurate (about 5\%) and subjects the patient to an extremely low dose of radiation (spine and hip scan-mrem). DEXA assesses integral bone mineral (cortical and trabecular bone) in whole body, spine, hip and forearm.

Table 1: WHO osteoporosis classification

\begin{tabular}{|c|c|}
\hline Diagnosis & T-score \\
\hline Normal & $>-1.0$ \\
\hline Osteopenia & $<-1.0,>-2.5$ \\
\hline Osteoporosis & $<-2.5$ \\
\hline Severe osteoporosis & $<-2.5$ plus fragility fractures \\
\hline
\end{tabular}

\section{Materials and Methods}

Our study is a prospective study conducted in Coimbatore during the period 2012-2017 carried out in low income group women having a sample size of 500 in numbers, for the diagnosis of osteoporosis, using DEXA Scan at Coimbatore.
Position of the subject for bone density scan is supine. The rectilinear scanning gives online bone image of the AP spine in L1-L4 on the computer monitor.

Bone mineral content is found by tracing the profiles along the edges of the bone image. BMD is the ratio of bone mineral content per scanned area. Bone mineral density (BMD) scan of spine in lumbar region (L1-L4) is carried out in 500 low socioeconomic group of women (age range $40-70$ years, mean age $=54.8 \pm 10.4$ years $)$. T-score and Zscore are calculated. Bone mass expressed as T-score, is the most significant parameter for the assessment and diagnosis of osteoporosis.

\section{Results}

\section{Age Distribution}

In our study, the age group is from 41 years to 70 years. Most of the patients are from 51-60 years representing 52 percent of the study group (Table 2). Osteoporosis and osteopenia were assessed using BMD at the level of hip and spine. While the age advances after 65 years the osteopenia is replaced by osteoporosis (Table 2).

Table 2: Age wise distribution of the BMD results

\begin{tabular}{|c|c|c|c|c|c|}
\hline \multirow[t]{2}{*}{ Age (yrs) } & \multirow[t]{2}{*}{ Number (\%) } & \multicolumn{2}{|l|}{ Spine } & \multicolumn{2}{|l|}{ Hip } \\
\hline & & Osteopenia & osteoporosis & Osteopenia & osteoporosis \\
\hline $41-45$ & $60(12)$ & 20 & Nil & 10 & Nil \\
\hline $46-50$ & $80(16)$ & 30 & 10 & 20 & 10 \\
\hline $51-55$ & $140(28)$ & 60 & 40 & 70 & 30 \\
\hline $56-60$ & $120(24)$ & 50 & 60 & 60 & 30 \\
\hline $61-65$ & $60(12)$ & 20 & 40 & 30 & 30 \\
\hline $66-70$ & $40(8)$ & Nil & 40 & Nil & 40 \\
\hline Total & $500(100)$ & $180(36 \%)$ & $190(38 \%)$ & $190(38 \%)$ & $140(28 \%)$ \\
\hline
\end{tabular}

In our study group of 500 cases, the prevalence of osteoporosis and osteopenia by spine BMD (74\%) is higher than BMD done at hip (66\%). As per the BMD at the level of spine 130 persons were normal while 170 persons were normal as per the $\mathrm{BMD}$ at the level of hip region giving an impression that the osteoporosis start early at the level of spine than the hip region (Table 3).

Table 3: Comparision of spine and hip BMD results

\begin{tabular}{|c|l|l|l|l|l|l|}
\hline \multirow{2}{*}{$\begin{array}{c}\text { Total number } \\
\text { of patients }\end{array}$} & \multicolumn{2}{|l|}{ Spine BMD } & \multicolumn{2}{l|}{ Hip BMD } \\
\cline { 2 - 7 } & Normal & Osteopenia & Osteoporosis & Normal & Osteopenia & Osteoporosis \\
\hline 500 & 130 & 180 & 190 & 170 & 190 & 140 \\
\hline
\end{tabular}

Table 4: Comparison of anthropometric data of study groups

\begin{tabular}{|l|c|c|c|c|}
\hline & $\begin{array}{c}\text { Normal weight } \\
(\text { BMI 18-25) }\end{array}$ & $\begin{array}{c}\text { Obese } \\
(\text { BMI 25-30) }\end{array}$ & $\begin{array}{c}\text { Severely obese } \\
(\text { BMI > 30) }\end{array}$ & P value \\
\hline Age & 54.46 & 52.68 & 51.1 & NS \\
\hline BMD g/cm2 & 0.732 & 0.843 & 0.815 & $<0.001$ \\
\hline
\end{tabular}

Our patients were grouped into 3 based on body mass index into normal, obese and severely obese (Table 4). Mean BMD of the normal weight when compared with mean BMD of obese and severely obese respectively was significantly different ( $\mathrm{P}$ value $<0.001)$. The BMD was found to be significantly higher in obese and severely obese women as compared to the BMD of normal weight women. But the mean BMD values of obese and severely obese groups did not differ significantly. 
Table 5: Descriptive statistics of participating subjects

\begin{tabular}{|l|c|c|c|c|}
\hline & Minimum & Maximum & Mean & Std. Deviation \\
\hline Age $(\mathrm{yrs})$ & 41 & 70 & 54.8 & 9.2 \\
\hline Weight $(\mathrm{kg})$ & 33.2 & 90 & 62.4 & 11.2 \\
\hline Height $(\mathrm{cm})$ & 135 & 167 & 152.7 & 6.3 \\
\hline BMI $(\mathrm{Kg} / \mathrm{m} 2)$ & 14.8 & 41.1 & 27.0 & 4.6 \\
\hline Menopause age (age) & 41 & 58 & 47 & 3.9 \\
\hline Femur BMD (g/cm2) & 0.407 & 1.054 & 0.765 & 0.158 \\
\hline $\begin{array}{l}\text { Femur } \\
\text { T-score }\end{array}$ & -4.4 & 0.9 & -1.61 & -1.92 \\
\hline Spine BMD & 0.564 & 1.194 & 0.796 & 0.197 \\
\hline $\begin{array}{l}\text { Spine } \\
\text { T-Score }\end{array}$ & -4.4 & 1.3 & -2.28 & 1.214 \\
\hline
\end{tabular}

The mean T-score by BMD at spine and hip are -2.28 and -1.61 respectively which belonged to osteoporosis as per WHO definitions for Osteoporosis.

Table 6: Comparison of prevalence of osteoporosis among premenopausal and post menopausal women

\begin{tabular}{|l|c|c|}
\hline & Premenopausal women & Menopausal women \\
\hline Osteopenia & $33.3 \%(20)$ & $36.3 \%(158)$ \\
\hline Osteoporosis & Nil & $43.2 \%(190)$ \\
\hline
\end{tabular}

In our study there were 60 menstruating and 440 postmenopausal women. There was increased prevalence of osteoporosis and osteopenia among postmenopausal women than menstruating women (Table 6).

Table 7: Previous studies measuring BMD using DEXA scan

In 2000, the Canadian multicentre osteoporosis study (CaMos), Canada.

In 2005, P.D. Hinduja Hospital, Mumbai

In 2007,Dept of public health, china.

In2010, Maharashtra, India

\section{Discussion}

Among total of 500 women of low socioeconomic status $36 \%$ were osteopenia $38 \%$ were osteoporotic by spine BMD and $38 \%$ were ostopenia and $28 \%$ were osteoporotic by hip BMD. Out Of 180 osteopenic women $11.1 \%$ were in the age group $41-45$ years and $16.6 \%$ in the age group of $46-50$ years and $33.3 \%$ in the age group of $51-55$ and $27.7 \%$ in the age group of $56-60$ and $11.1 \%$ were in the age group of $61-$ 66years. Out of 190 osteoporotic women $5.2 \%$ were in the
BMD of lumbar spine and femoral neck were measured by DEXA scan. BMD of lumbar spine in 578 women and 467 men, prevalence of osteoporosis in Canadian women was $15.8 \%$ and men was $6.6 \%$. Their prevalence are very low compared to Indian population.

In a series of 200 patient group women above $40 y$ rs BMD done, after the age of 60 years there was an almost 100\% incidence of either osteopenia or osteoporosis. In the age group between 40 and 65 years, the incidence of osteopenia was $34 \%$ and osteoporosis was $8 \%$ together was $42 \%$. The incidence of osteoporosis in their study was $8 \%$ and osteopenia $34 \%$.

In 4148 subjects, (1810 men \& 2338 women) Korean adults aged 20-79yrs. The prevalence of osteoporosis among age group 50-79yrs women, BMD at lumbar spine and femur was $40.1 \%$ \& $12.4 \%$. in women peak BMD occurred in the age range 40-49 years for femoral neck and 30-39 years for lumbar spine. .

In 264 subjects age group 21 to 61 years (both sexes) BMD scan was done. Highest prevalence of osteoporosis was seen in the age group 61 and above $(42.86 \%)$ followed by age group $51-60$ years and $41-50$ years as $33.33 \%$ and $29.90 \%$ respectively. Overall Osteoporosis and osteopenia was seen in $23.33 \%$ and $26 \%$ males respectively while the two conditions among female stood at $34.21 \%$ and $37.72 \%$ respectively

age group $46-50$ years and $21 \%$ in the age group of $51-55$ years and $31.5 \%$ in the age group of $56-60$ and $21 \%$ in the age group of 61-65 and 21\% were in the age group of 66-70. So $38 \%$ were osteoporotic and $36 \%$ were osteopenic. Our study shows that above the age of 50 years there is an almost $90 \%$ prevalence of either osteopenia or osteoporosis.

Overall, in the age group of between 41 and 70 years, the prevalence of osteopenia (36\%) and osteoporosis (38\%) together was $74 \%$ which is quite significant and showed they are above than those reported from developed countries 
(Table 7). Moreover there are limited studies in India using DEXA scan (Table 7).

Among 60 menstruating women, there was 20(33.3\%) osteopenic women and no one was osteoporotic and among 440 postmenpausal women, $160(36.3 \%)$ were osteopenic and $190(43.2 \%)$ were osteoporotic. Our study showed an increased prevalence of osteoporosis and osteopenia among postmenopausal women than among menstruating women, results were similar to other Indian studies (Table 7).

There was significant difference between mean BMD of the normal weight when compared with mean BMD of obese and severely obese women ( $\mathrm{P}$ value $<0.001)$. The BMD was found to be significantly higher in obese and severely obese women as compared to the BMD of normal weight women. But the mean BMD values of obese and severely obese groups did not differ significantly.

The worldwide incidence of osteoporosis is rising because of increase in the aging population and sedentary lifestyle. Approximately 60 million people at present have osteoporosis in India. The rate of hip fractures is expected to triple over the next three decades. ${ }^{9,10}$ Once the woman is in her fifth decade, there is a gradual loss of BMD. It is noteworthy that there is considerable increase in bone loss during the 5 years immediately following menopause.

The orthopaedic surgeon plays an important role in establishing a biological zero in each perimenopausal patient and in controlling the rate of bone loss during postmenopausal period by early detection, and in calcium supplementation and other drugs.

\section{Conclusion}

In summary, low BMD and low T- Score has been demonstrated in our study as an important predictor of future fracture risk in women above 40 years. The women from the low-income group engaged in repetitive work. Load-bearing activities were not associated with better bone health probably due to the absence of adequate nutrition. Osteoporosis and bone thinning sets in early $5^{\text {th }}$ decade of life which may explain the early onset of fractures.

About $80 \%$ of the women in this group were independently doing their activities on their own and $20 \%$ of them were doing their household activities. In spite of that, overall in the age group between 41 and 70 years, the prevalence of osteopenia (36\%) and osteoporosis (38\%) together was $74 \%$ which is quite significant and showed they are above than western countries. Bone health is expensive to monitor, more difficult to treat, and by the time osteoporosis and fracture sets in, the condition is irreversible. Bone mineral density (BMD) by DEXA scan is the best available means to assess bone strength and the only important tool in the early diagnosis of osteoporosis, so that effective preventive and therapeutic measures can be initiated at the earliest.

\section{Conflict of Interest: None.}

\section{References}

1. Dorothy A. N, Molloy R., and Kleerekoper, M. Prevalence of osteoporosis in women referred for bone density testing. J Clin Densitometer 1998;1:5-11.

2. Shatrugna V, Kulkarni B., Kumar P. A. Bone status of Indian women from a low income group and its relationship to the nutritional status. Osteop Int 2005;16:1827.

3. National Osteoporosis Foundation. Osteoporosis. Review of the evidence for prevention, diagnosis and treatment and costeffective analysis. Osteop Int 1998;8(4):S1-S88

4. Follin S. L., Hansen L. B. Current approaches to the prevention and treatment of postmenopausal osteoporosis. Am J Health Syst Pharm 2003;60(9):883-901.

5. Syed Z, Khan A. Bone densitometry: applications and limitations. J Obstet Gynaecol Can 2002;24:476-84.

6. McBride J. F., and Miller C. T. Nondestructive measurement of phase fractions in multiphase porous-media experiments by using x-ray attenuation, Centre for Multipahse Research News. 1994;1:1-5.

7. Price R. I., M. J. Walters. Impact of the analysis of a bone density reference range on determination of the T-score. J Clin Densiton 2003;6(1):51-62.

8. Watts N. B. Fundamentals and pitfalls of bone densitometry using dual-energy X-ray absorptiometry (DXA). Osteoporos Int 2004;5(11):847-54.

9. Kannus P, Niemi S, Parkkari J. Hip fractures in Finland between 1970 and 1997, and predictions for the future. Lancet 1999;353:802-5.

10. Willig R, Keinanen-Kiukaaniemi S, Jalovaara P. Mortality and quality of life after trochanteric hip fracture. Public Health 2001;115:323-7.

How to cite this article: Louis $\mathrm{P}$, Sengodan VC, Kumar NT, Achar ST. Evaluation of osteoporosis using DEXA scan among low income group women in South India. Indian J Orthop Surg 2019;5(2):145-8. 